\title{
Pharmacological treatment of osteoporosis in the oldest old
}

This article was published in the following Dove Press journal:

Clinical Interventions in Aging

6 July 2017

Number of times this article has been viewed

\author{
A Vandenbroucke' \\ FP Luyten ${ }^{2,3}$ \\ J Flamaing ${ }^{4}$ \\ E Gielen ${ }^{3,4}$ \\ 'Clinical Department of Internal \\ Medicine, UZ Leuven, ${ }^{2}$ Skeletal Biology \\ and Engineering, Department of \\ Development and Regeneration, KU \\ Leuven, ${ }^{3}$ Center for Metabolic Bone \\ Disease, UZ Leuven, ${ }^{4}$ Gerontology \\ and Geriatrics, Department of \\ Clinical and Experimental Medicine, \\ KU Leuven, Leuven, Belgium
}

\begin{abstract}
The incidence of osteoporotic fractures increases with age. Consequently, the global prevalence of osteoporotic fractures will increase with the aging of the population. In old age, osteoporosis is associated with a substantial burden in terms of morbidity and mortality. Nevertheless, osteoporosis in old age continues to be underdiagnosed and undertreated. This may, at least partly, be explained by the fact that evidence of the antifracture efficacy of osteoporosis treatments comes mainly from randomized controlled trials in postmenopausal women with a mean age of 70-75 years. However, in the last years, subgroup analyses of these landmark trials have been published investigating the efficacy and safety of osteoporosis treatment in the very elderly. Based on this evidence, this narrative review discusses the pharmacological management of osteoporosis in the oldest old ( $\geq 80$ years). Because of the high prevalence of calcium and/or vitamin D deficiency in old age, these supplements are essential in the management of osteoporosis in the elderly people. Adding antiresorptive or anabolic treatments or combinations, thereof, reduces the risk of vertebral fractures even more, at least in the elderly with documented osteoporosis. The reduction of hip fracture risk by antiresorptive treatments is less convincing, which may be explained by insufficient statistical power in some subanalyses and/or a higher impact of nonskeletal risk factors in the occurrence of hip fractures. Compared with younger individuals, a larger absolute risk reduction is observed in the elderly because of the higher baseline fracture risk. Therefore, the elderly will benefit more of treatment. In addition, current osteoporosis therapies also appear to be safe in the elderly. Although more research is required to further clarify the effect of osteoporosis drugs in the elderly, especially with respect to hip fractures, there is currently sufficient evidence to initiate appropriate treatment in the elderly with osteoporosis and osteoporotic fractures.
\end{abstract}

Keywords: oldest old, vulnerability, antiresorptives, anabolics, efficacy, safety

\section{Osteoporosis and osteoporotic fractures in old age: a challenge}

Along with the aging of the population, the incidence of age-associated conditions increases, and more attention and resources are required for the management of these disorders in the elderly. Osteoporosis is a systemic skeletal disease characterized by low bone mass and microarchitectural deterioration of bone tissue, with a consequent increase in bone fragility and fracture risk. ${ }^{1}$ The incidence of osteoporotic fractures increases with age, and osteoporosis in old age is a challenge because of the extent of the problem and the significant burden in terms of morbidity, mortality, and economic cost. Today, the cumulative incidence of hip fractures in women aged 80 years is $\sim 30 \%{ }^{2}$ Vertebral fractures are even more common, with a prevalence of $\sim 20 \%$ in women aged $>75$ years and $>40 \%$ in women aged $>80$ years. $^{3}$ In addition, the number of nonhip nonvertebral fractures such as fractures of the proximal humerus
Correspondence: E Gielen

Gerontology and Geriatrics,

Department of Clinical and Experimental

Medicine, UZ Leuven, Herestraat 49,

3000 Leuven, Belgium

$\mathrm{Tel}+3216340931$

Fax +32 I6 342641

Email evelien.gielen@uzleuven.be
Clinical Interventions in Aging 2017:12 1065-1077

1065

Dovepress f in $\mathbf{0}$

http://dx.doi.org// $0.2147 /$ CIA.SI 31023 (c) (1) (\$) $\odot 2017$ Vandenbroucke et al. This work is pulished and licensed by Dove Medical Press Limited. The full terms of this license are available at https://www.dovepress.com/terms.php

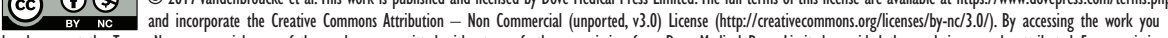
hereby accept the Terms. Non-commercial uses of the work are permitted without any further permisision from Dove Medical Press Limited, provided the work is properly atributed. For permission for commercial use of this work, please see paragraphs 4.2 and 5 of our Terms (https://www.dovepress.com/terms.php). 
increases dramatically with age, particularly in women aged $>80$ years. ${ }^{4}$ Women aged $>80$ years account for $>30 \%$ of all osteoporotic fractures and even $>60 \%$ of all nonvertebral fractures. ${ }^{5}$

Age is one of the main determinants of not only the absolute risk of fracture, but also the type of osteoporotic fracture. Between the ages of 55 and 75 years, postmenopausal women are at more risk of vertebral fractures than any other type of fracture, but at the age of $>75$ years, they become increasingly at a risk of hip fracture and other nonvertebral fractures. ${ }^{6}$

The burden of osteoporosis will only increase in the future because of the aging of the population. In Belgium, it is expected that in the next 10 years, the number of osteoporotic fractures will increase with $25 \%$, from $\sim 80.000$ per year to $>98.000$ per year. $^{7}$

\section{Elderly persons with osteoporotic fractures are frail}

Elderly patients with osteoporotic fractures are not "average" elderly persons but should be considered as frail elderly, with a high prevalence of underlying comorbidities. ${ }^{8}$ Indeed, in old age, osteoporosis and osteoporotic fractures tend to occur in a particularly frail subset of population. ${ }^{9}$ This frailty will be reflected in poor postfracture outcomes, such as mortality, functional decline, and loss of quality of life. For example, within 1 year after a hip fracture, $40 \%$ of patients were unable to walk independently, $33 \%$ of them were totally dependent or in a nursing home, and mortality was $\sim 20 \% .{ }^{10-12}$ Similar observations were found, to some extent, in the elderly with other types of nonvertebral fractures and even with vertebral fractures. ${ }^{13}$ In patients with hip fracture, this excess mortality is not only observed within the first year following the fracture but continuously observed in the years thereafter because of the underlying comorbidities in these frail elderly. ${ }^{14}$

\section{Underdiagnosis and undertreatment of osteoporosis in old age}

Despite the increasing evidence for the high prevalence and severity of osteoporosis in the elderly, osteoporosis continues to be underdiagnosed and undertreated in old age. Even in older individuals admitted to the hospital with documented fractures, physicians continue to underuse the available treatment options, particularly in women aged $>80$ years. $^{15}$

Since elderly persons with osteoporosis constitute a particularly frail subset of population, there is an urgent requirement for convenient treatment options with documented efficacy and safety. Available osteoporosis treatments should be proven to be effective in the elderly, not only against vertebral fractures but even more so against nonvertebral fractures, as these account for most of the morbidity and mortality associated with osteoporosis in old age. Treatment options should also be proven to be safe in the elderly who are frail, with underlying comorbidities, and at an increased risk of adverse events.

\section{Treatment of osteoporosis in the oldest old}

In the following sections, the existing evidence on efficacy and safety of the currently available treatment options for osteoporosis in the oldest old ( $\geq 80$ years) is evaluated. Of note, nonpharmacological interventions such as fall prevention strategies play an essential role in the management of osteoporosis, also in the elderly, but are outside the scope of this manuscript.

\section{Calcium and vitamin D supplementation in old age}

One of the main determinants of bone loss and fracture risk in old age is calcium and vitamin D deficiency; therefore, combined supplementation of calcium and vitamin D has become one of the main components for reducing bone loss and fracture risk in old age.

Vitamin D deficiency is commonly defined as a serum level of 25-hydroxyvitamin D (25OHD) of $<20 \mathrm{ng} / \mathrm{mL}$, and although there is much controversy about this threshold, ${ }^{16}$ it is clear that low levels of 25OHD occur in all age-groups. In European countries, for example, $2 \%-30 \%$ of adults have a serum $25 \mathrm{OHD}$ level of $<10 \mathrm{ng} / \mathrm{mL}$, but this may rise to $>80 \%$ in the institutionalized elderly. ${ }^{17}$ In fact, a gradual decrease of $25 \mathrm{OHD}$ is observed from healthy adults over independent elderly to institutionalized persons and patients with hip fracture. ${ }^{17}$ Despite the observation that the intestinal absorption of vitamin $\mathrm{D}_{3}$ and its metabolism into 25OHD and the biologically active metabolite 1,25-dihydroxyvitamin D $\left(1,25(\mathrm{OH})_{2} \mathrm{D}_{3}\right)$ is well preserved in the elderly without liver disease or kidney failure, these individuals are at a risk of hypovitaminosis D because of low vitamin D dietary intake and decreasing capacity of the skin to produce vitamin $\mathrm{D}_{3}$, together with less outdoor activities and sun exposure. ${ }^{17,18}$ Therefore, unsurprisingly, the elderly and especially those in institutions have lower levels of 25OHD than that of young individuals from the same geographic region. ${ }^{19}$ Hypovitaminosis D lowers the intestinal calcium absorption and leads to a negative calcium balance, which may be enhanced by insufficient dietary calcium intake. This stimulates the secretion of parathyroid hormone (PTH; age-related hyperparathyroidism), 
which enhances bone turnover, advances osteoporosis, and increases fracture risk. ${ }^{20}$ Poor vitamin D status may also increase fracture risk by increasing the risk of falling apparently through an effect on muscle strength. ${ }^{21}$

Adequate vitamin D status is therefore essential in the prevention of falls as well as bone loss and osteoporotic fractures. In order to reduce the risk of falls, a daily intake of $800-1,000 \mathrm{IU}$ of vitamin D is recommended. ${ }^{22}$ There is indeed ample evidence of the effect of vitamin D supplementation at a dose of $800-1,000$ IU on fall reduction. ${ }^{23}$ Therefore, the International Osteoporosis Foundation and the American Geriatrics Society recommend vitamin D supplementation of at least 1,000 IU in the community-dwelling and institutionalized elderly. ${ }^{22,24}$ In older adults, 800-1,000 IU of vitamin D is the estimated average to reach a serum $25 \mathrm{OHD}$ level of $30 \mathrm{ng} / \mathrm{mL}$ ( $75 \mathrm{nmol} / \mathrm{L})$, which is required to reduce the risk of falls and fall-related injuries. ${ }^{22,25}$ Considerable higher doses up to 4,000 IU per day would be required to ensure that almost all (92\%) older adults reach this level of $30 \mathrm{ng} / \mathrm{mL} .{ }^{22,24}$ However, the efficacy of doses $>1,000 \mathrm{IU}$ per day for falls has not been demonstrated in randomized controlled trials (RCTs). For example, in patients with hip fracture, a daily intake of 2,000 IU of vitamin D was not more effective than $800 \mathrm{IU}$ per day to prevent falls. ${ }^{26}$ In contrast, it has recently been shown that an intermittent very high dose of vitamin D such as a single oral dose of 500,000 IU per year increases the risk of falls, especially in the first 3 months when serum $25 \mathrm{OHD}$ level increased to $>45 \mathrm{ng} / \mathrm{mL}(112 \mathrm{nmol} / \mathrm{L})$. Furthermore, another recent trial showed that a monthly high dose of vitamin D $(60,000$ IU per month) increased the risk of falls compared with 24,000 IU per month. ${ }^{27}$ Therefore, at this time, it is premature to recommend intakes $>1,000 \mathrm{IU}$ of vitamin $\mathrm{D}$ per day for all older adults to prevent falls. ${ }^{22,23}$

There is much controversy about the threshold level of serum 25OHD for bone health and, thus, the optimal intake of vitamin D to prevent bone loss and osteoporotic fractures. The Institute of Medicine recommends a daily intake of 800 IU of vitamin D for those aged $\geq 71$ years in order to achieve a serum 25OHD level of at least $20 \mathrm{ng} / \mathrm{mL}$ $(50 \mathrm{nmol} / \mathrm{L})$ as this meets the requirement of at least $97.5 \%$ of the population. ${ }^{28,29}$ In contrast, in its 2011 guideline, the Task Force of the Endocrine Society recommends a serum $25 \mathrm{OHD}$ level $>30 \mathrm{ng} / \mathrm{mL} .{ }^{30}$ However, a serum 25OHD level $>20 \mathrm{ng} / \mathrm{mL}$ is sufficient to normalize surrogate endpoints of bone health such as $1,25(\mathrm{OH})_{2} \mathrm{D}_{3}, \mathrm{PTH}$, intestinal calcium absorption, and bone mineral density (BMD). There is no convincing proof of additional benefit on bone health with a serum $25 \mathrm{OHD}$ level $>30 \mathrm{ng} / \mathrm{mL}{ }^{23}$
In addition, there is an ongoing intense debate whether vitamin $\mathrm{D}$, in combination with calcium, does indeed reduce the risk of osteoporotic fractures. ${ }^{31,32}$ Yet, although it is clear that vitamin $\mathrm{D}$ alone does not reduce fracture risk, ${ }^{33-36}$ strong scientific evidence supports its beneficial effect in combination with calcium. ${ }^{34,35}$ In addition to an insufficient dose of calcium and vitamin D supplementation as well as therapeutic incompliance, which may be as high as 40\%-60\% even in relatively healthy study participants, ${ }^{37,38}$ another reason why individual RCTs and meta-analyses failed to demonstrate a reduction in fracture risk with calcium and vitamin D may be the lack of targeting the population at a risk of a negative calcium balance and/or vitamin D deficiency. ${ }^{23,39}$ Indeed, calcium and vitamin D supplementation needs to be directed to persons with documented or at a risk of calcium and/or vitamin D deficiency, which is highly prevalent in people aged $\geq 75$ years and in institutionalized persons. ${ }^{17} \mathrm{~A}$ recent meta-analysis, for example, found that vitamin D coadministered with calcium reduced the risk of hip fractures in institutionalized, but not in community-dwelling elderly. ${ }^{31}$

In recent years, safety questions have been raised about the use of supplemental calcium with and without vitamin D, because of a potential increased cardiovascular risk with calcium supplements. ${ }^{40,41}$ Currently, there is no conclusive evidence that calcium supplements increase cardiovascular risk. Nevertheless, it seems appropriate to correct calcium deficiency preferably by enhancing dietary intake and to direct supplementation to the aforementioned subgroups that will most benefit from the supplementation. However, individuals who do not obtain sufficient dietary calcium intake should not be advised to avoid calcium supplements because of concerns about an increased cardiovascular risk. ${ }^{42}$

Thus, the combined supplementation of calcium and vitamin $\mathrm{D}$ has become an essential component to reduce bone loss and fracture risk in elderly individuals. However, osteoporosis treatment, on top of calcium and vitamin D, should be considered in the elderly with osteoporosis and osteoporotic fractures. In the following section, the evidence on the efficacy (Table 1) and safety (Table 2) of the currently available osteoporosis treatments in the oldest old is discussed.

\section{Pharmacological osteoporosis treatment in old age \\ Efficacy of osteoporosis drugs}

Alendronate

The efficacy of alendronate as an antiresorptive agent was established by the Fracture Intervention Trial (FIT). The FIT 


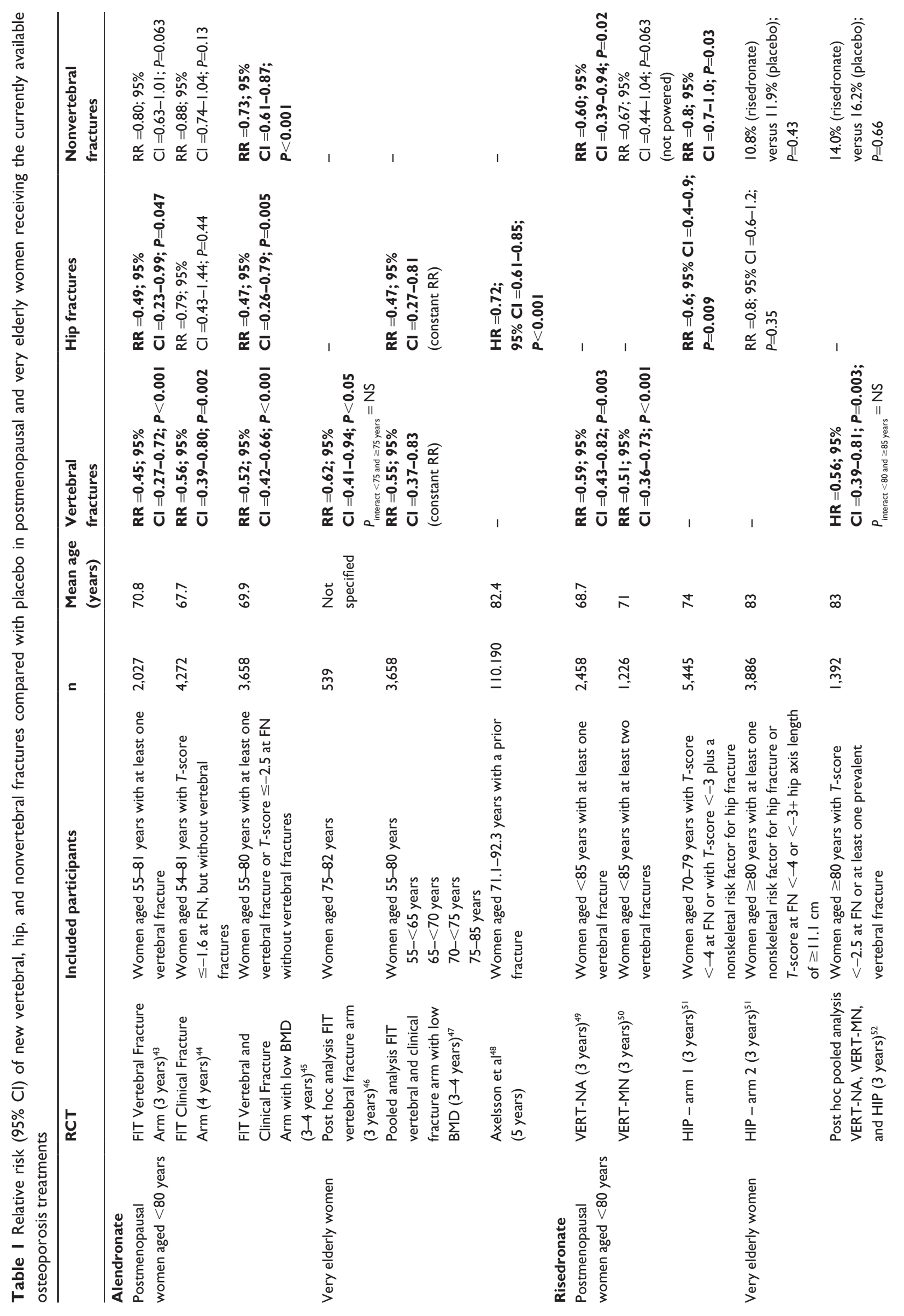




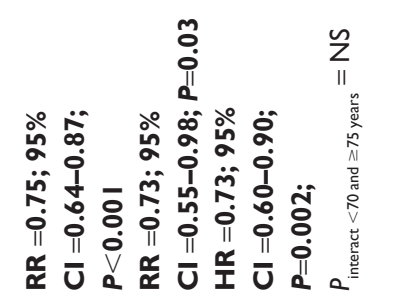

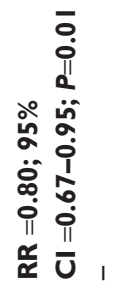

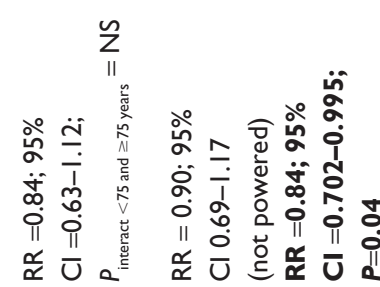

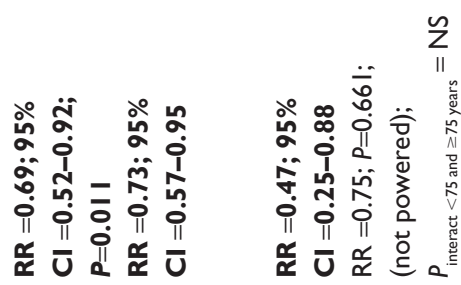

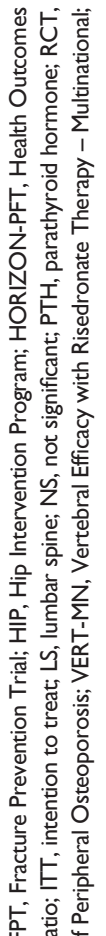

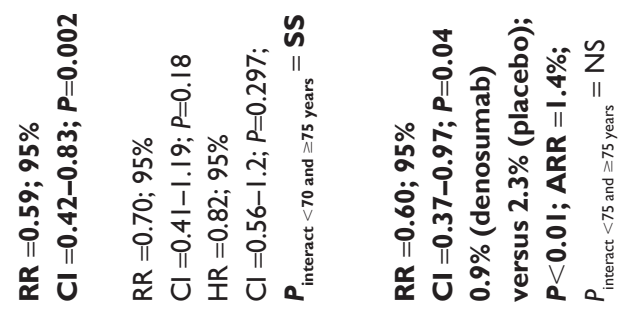

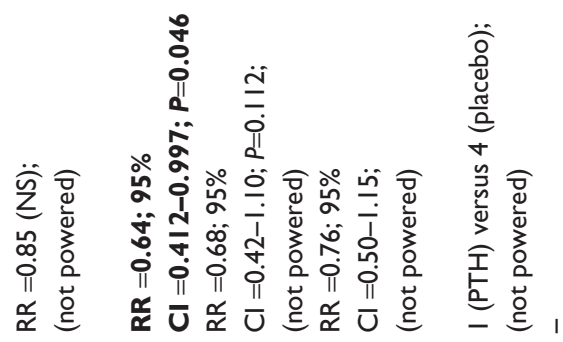

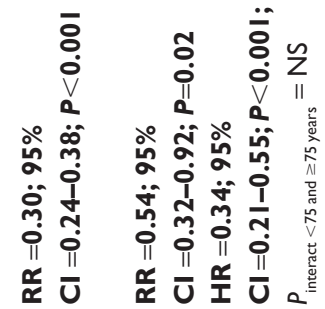
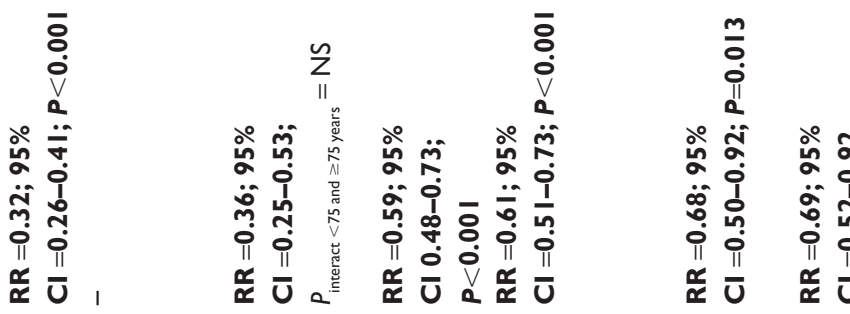

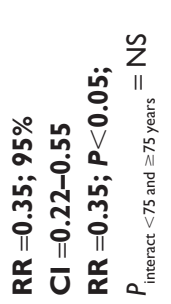

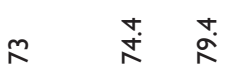

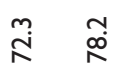

$\stackrel{\infty}{\infty}$

\%ั.

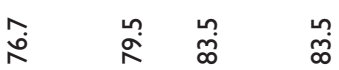

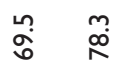

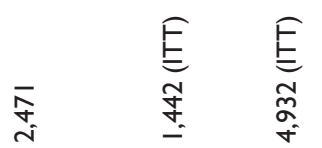

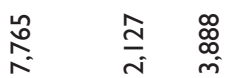

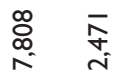

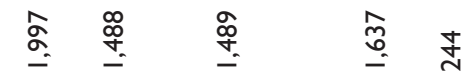

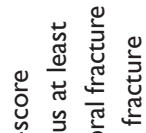

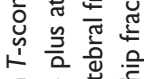

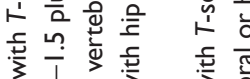

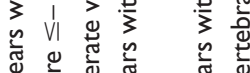

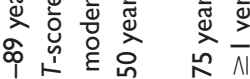

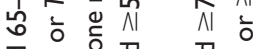

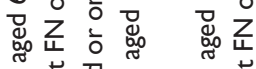

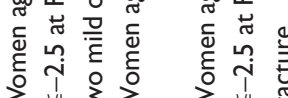

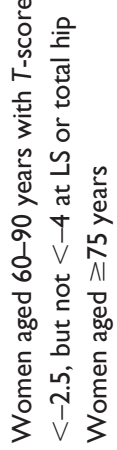

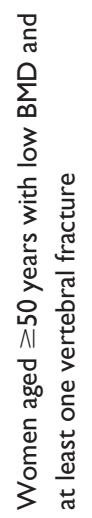
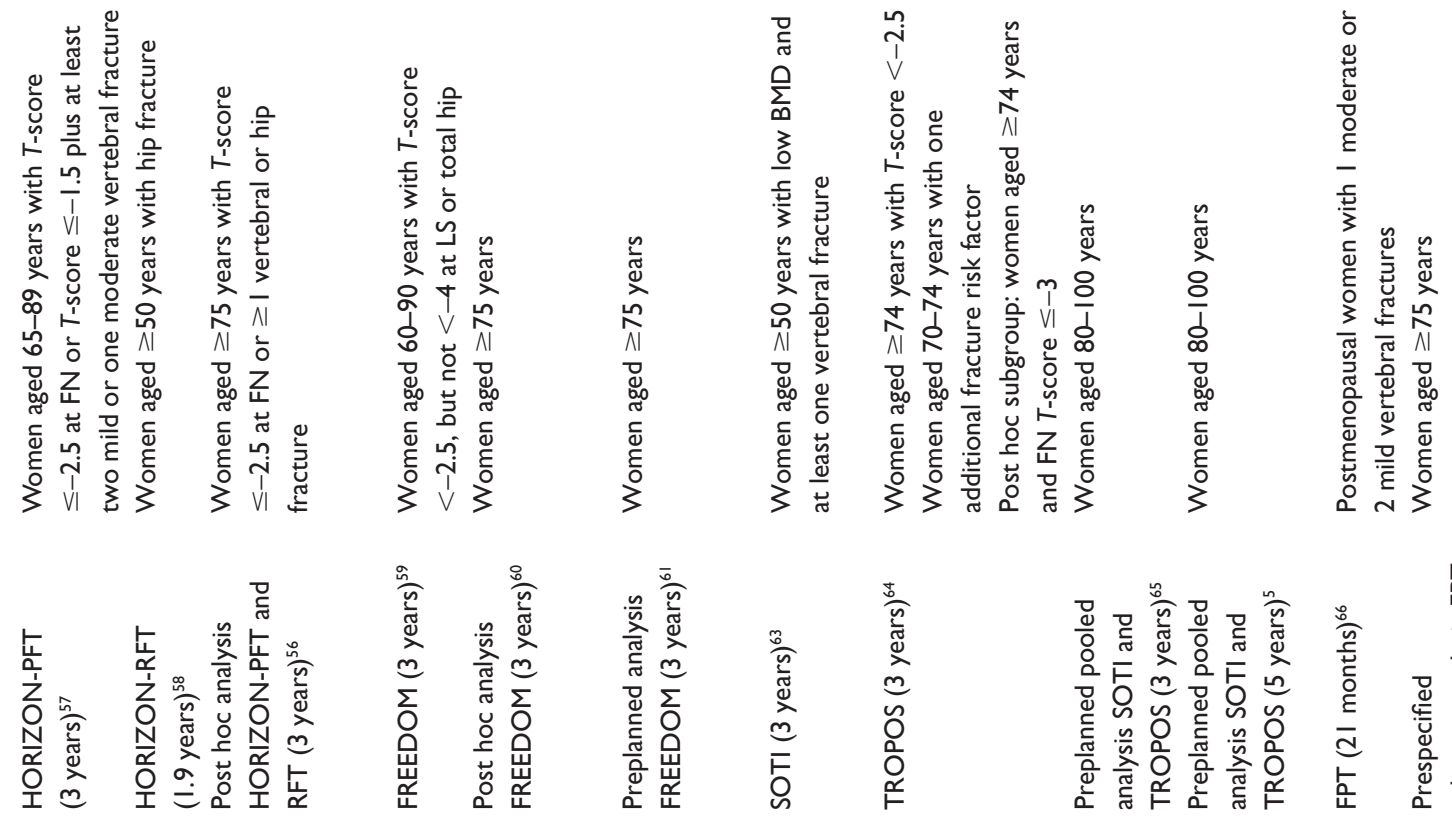

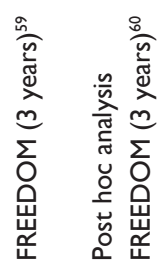
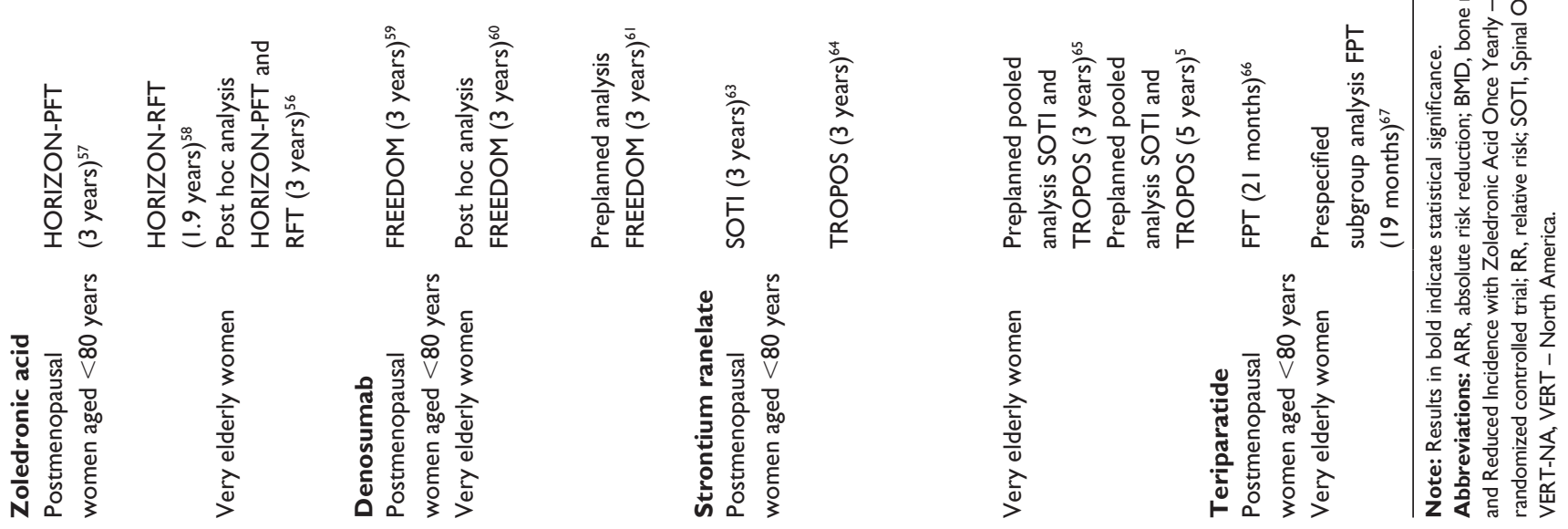


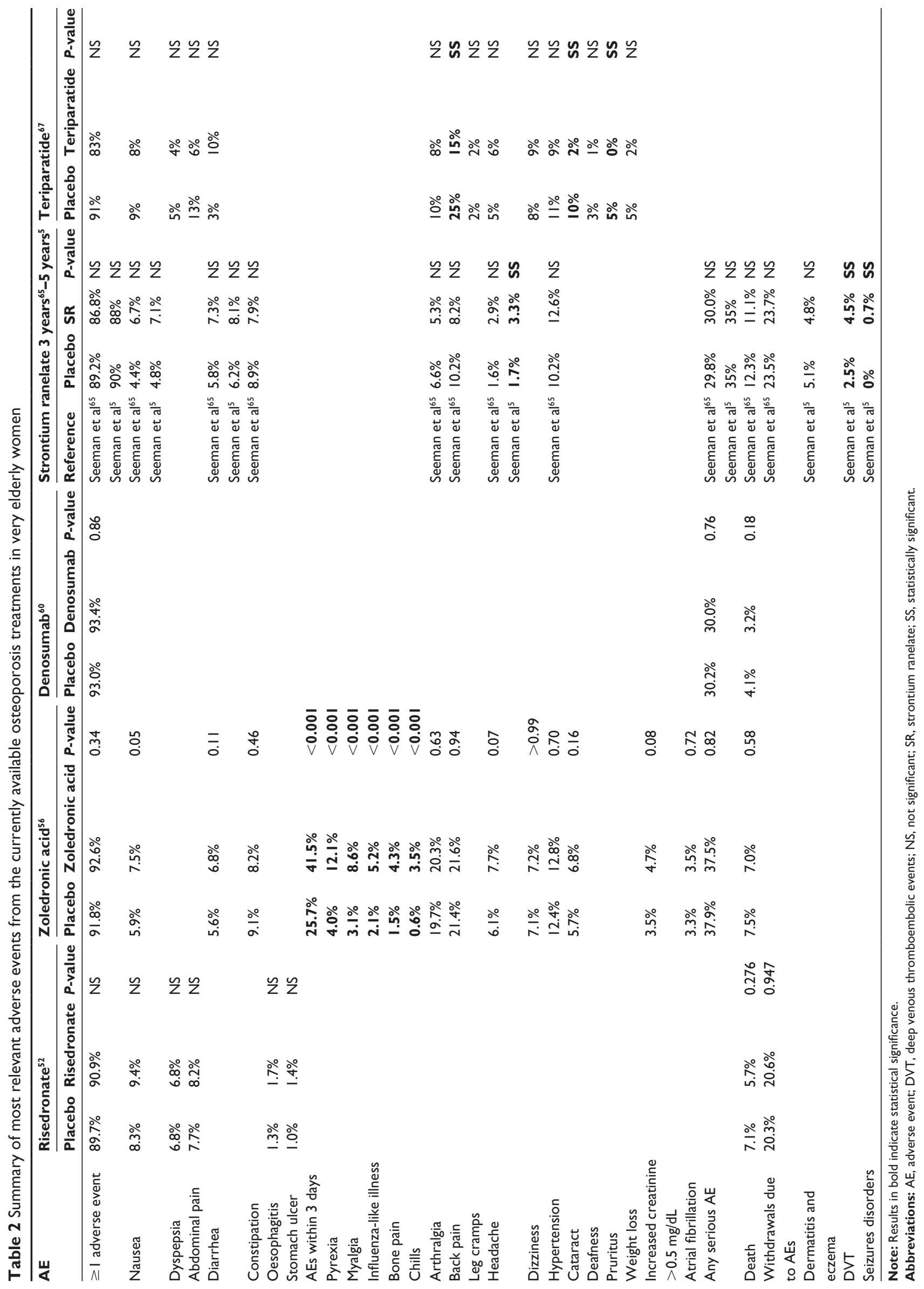


Vertebral Fracture Arm (FIT-I) included postmenopausal women with a prevalent vertebral fracture, ${ }^{43}$ whereas the FIT Clinical Fracture Arm (FIT-II) included postmenopausal women with a $T$-score $\leq-1.6$ at the femoral neck (mean age $=70.8$ years and 67.7 years, respectively). ${ }^{44}$ The third analysis of the FIT investigated the effect of alendronate in postmenopausal women with an existing vertebral fracture or with a $T$-score $\leq-2.5$ at the femoral neck, but without vertebral fractures (mean age $=69.9$ years). ${ }^{45}$

A post hoc analysis of the FIT-I by Ensrud et al has evaluated the antifracture efficacy of alendronate in postmenopausal women with the highest fracture risk. ${ }^{46}$ This analysis included a subgroup of patients aged $\geq 75$ years (range $=75-82$ years). After 3 years, alendronate significantly reduced the risk of vertebral fracture by $38 \%$ (relative risk $[\mathrm{RR}]=0.62 ; 95 \%$ confidence interval $[\mathrm{CI}]=0.41-0.94)$ in women aged $\geq 75$ years, compared with $51 \%$ in the younger population $(\mathrm{RR}=0.49 ; 95 \% \mathrm{CI}=0.35-0.68)$. In order to prevent one new vertebral fracture, 8 women aged $\geq 75$ years needed to be treated with alendronate compared with 9 women aged $<75$ years.

The post hoc analysis of the FIT-I by Ensrud et al was followed by an analysis based on the pooled data from both FIT arms. ${ }^{47}$ The aim of this analysis by Hochberg et al was to calculate age-specific fracture rates by the treatment group (ie, 55 to $<65$ years, 65 to $<70$ years, 70 to $<75$ years, and $75-85$ years). $\mathrm{RR}$ reductions for hip $(\mathrm{RR}=0.47 ; 95 \% \mathrm{CI}=0.27-0.81$; $P<0.01)$ and vertebral $(\mathrm{RR}=0.55 ; 95 \% \mathrm{CI}=0.37-0.83$; $P<0.01)$ fractures were constant among age-groups, with an even greater absolute risk reduction as age increases. This greater absolute risk reduction was explained by the agerelated increase in fracture risk in the placebo group. ${ }^{47}$

Finally, a very recent study by Axelsson et al showed that alendronate treatment in patients with a mean age of $82.4 \pm 8.3$ years with a prior fracture was associated with a reduced hip fracture risk (hazard ratio $(\mathrm{HR})=0.72 ; 95 \% \mathrm{CI}=0.61-0.85$; $P<0.001) .{ }^{48}$ The reduction in hip fracture risk was maintained across all age quartiles, and the absolute risk reduction at 5 years increased substantially by quartile of age.

These results illustrated that alendronate is an effective osteoporosis treatment in the elderly with proven vertebral and hip fracture reduction and also indicated that the elderly who have a higher baseline fracture risk benefit even more from osteoporotic treatment than younger persons. ${ }^{46,47}$

\section{Risedronate}

In 1999 and 2000, the Vertebral Efficacy with Risedronate Therapy (VERT) trials (VERT - North America [VERT-NA] and VERT - Multinational [VERT-MN]) demonstrated the efficacy of risedronate to prevent vertebral and nonvertebral fractures in postmenopausal women with one or more prevalent vertebral fractures (mean age $=\sim 70$ years). ${ }^{49,50}$ In 2001, the Hip Intervention Program (HIP) trial investigated the effect of risedronate on hip fracture risk in two different arms, of which the first arm included postmenopausal women with a mean age of 74 years. ${ }^{51}$

The second arm of the HIP trial included 3,886 women, aged $\geq 80$ years (mean age $=83$ years), with at least one nonskeletal risk factor for hip fracture (eg, poor gait or a propensity to fall) or a low BMD at the femoral neck. ${ }^{51}$ After 3 years, no significant reduction in the risk of hip fractures was observed $(\mathrm{RR}=0.8 ; 95 \% \mathrm{CI}=0.6-1.2 ; P=0.35)$. Of note, the majority $(58 \%)$ of the participants were selected based on the presence of a nonskeletal risk factor, whereas only $16 \%$ of them were selected based on low BMD.

A second analysis focusing on the elderly was a pooled analysis of the VERT-NA, VERT-MN, and HIP trials by Boonen et al. ${ }^{52}$ This analysis included 1,392 women aged $\geq 80$ (mean age $=83$ years) with osteoporosis $(T$-score $<-2.5$ or at least one prevalent vertebral fracture). The risk of vertebral fractures was reduced by $81 \%(\mathrm{HR}=0.19 ; 95 \%$ $\mathrm{CI}=0.09-0.40 ; P<0.001)$ after 1 year and by $44 \%(\mathrm{HR}=0.56$; $95 \% \mathrm{CI}=0.39-0.81 ; P=0.003$ ) after 3 years. For nonvertebral fractures, the incidence was not significantly different in the treatment group and the placebo group $(P=0.66)$.

This difference in benefit for vertebral versus nonvertebral fractures in the elderly in the analyses of both McClung et al and Boonen et al might be explained by the fact that bisphosphonates impact on BMD, proven by the significant reduction of vertebral fractures. However, bisphosphonates do not have impact on the nonskeletal risk factors of fractures such as gait disturbances, impaired balance, and fall risk. These nonskeletal factors are of particular importance in the occurrence of nonvertebral fractures, such as hip fractures, in the elderly who are more prone to falling. ${ }^{53}$ In contrast, vertebral fractures are often atraumatic, thus less influenced by these nonskeletal risk factors. An additional explanation for this discrepancy between the older and younger population in preventing nonvertebral fractures might be insufficient statistical power in the older age-group. ${ }^{52}$

\section{Zoledronic acid}

If administered inappropriately, the intake of oral bisphosphonates is associated with well-known gastrointestinal adverse events. ${ }^{54}$ Moreover, adherence to oral bisphosphonates is low: $\sim 50 \%$ of the patients to whom oral therapy is prescribed have discontinued the treatment after 1 year. ${ }^{55}$ These factors make parenteral zoledronic acid an attractive choice in the 
treatment of osteoporosis, especially in the elderly and disabled, demented, or frail patients in whom polypharmacy, nonadherence, and intolerance are most prevalent. ${ }^{56}$

The Health Outcomes and Reduced Incidence with Zoledronic Acid Once Yearly - Pivotal Fracture Trial (HORIZON-PFT) has shown that zoledronic acid is an effective treatment in postmenopausal osteoporotic women (mean age $=73$ years), with, after 3 years, a significant reduction in the risk of vertebral, hip, and nonvertebral fractures. ${ }^{57}$ In a subsequent analysis, the HORIZON-Recurrent Fracture Trial (HORIZON-RFT) in patients with a surgical repair of a low-trauma hip fracture (mean age $=74.4$ years), zoledronic acid significantly reduced the risk of new vertebral and nonvertebral fractures. ${ }^{58}$

In 2010, Boonen et al published a post hoc pooled analysis of the HORIZON-PFT and HORIZON-RFT focusing on the elderly. ${ }^{56}$ Inclusion criteria were postmenopausal women aged $\geq 75$ years (mean age $=79.4$ years) with osteoporosis $(T$-score $\leq-2.5$ at the femoral neck or $\geq 1$ prevalent vertebral or hip fracture). After 3 years, the incidence of vertebral and nonvertebral fracture was significantly lower in the zoledronic acid group than in the placebo group $(\mathrm{HR}=0.34 ; 95 \% \mathrm{CI}=0.21-0.55$; $P<0.001$ and $\mathrm{HR}=0.73 ; 95 \% \mathrm{CI}=0.6-0.9 ; P=0.002$, respectively). This benefit was comparable with the $\mathrm{RR}$ reduction in subjects aged $<75$ years in the HORIZON-PFT and HORIZON-RFT, presenting zoledronic acid as an effective treatment option for the prevention of vertebral and nonvertebral fractures in the elderly. However, in patients aged $\geq 75$ years, the incidence of hip fractures was lower with zoledronic acid, but this did not meet statistical significance $(\mathrm{HR}=0.82 ; 95 \%$ $\mathrm{CI}=0.56-1.2 ; P=0.297$ ), contrary to the statistical significance that was obtained in patients aged $<75$ years. Possibly the sample size was not statistically powered to detect hip fracture risk reduction in this older age-group. An alternative explanation is the greater influence of nonskeletal risk factors for hip fractures with increasing age. ${ }^{52,56}$

\section{Denosumab}

Denosumab has been established as a safe and effective intervention by the FREEDOM trial by Cummings et al, with a significant risk reduction of vertebral, hip, and nonvertebral fractures in postmenopausal women with a mean age of 72.3 years. ${ }^{59}$

A post hoc analysis of the FREEDOM trial was carried out by Boonen et al in 2011 to evaluate the effect of denosumab in high-risk populations, among which persons aged $\geq 75$ years. ${ }^{60}$ In this age-group (mean age $=78.2$ years), denosumab significantly reduced the risk of hip fractures by $62 \%(2.3 \%$ placebo versus $0.9 \%$ denosumab; $P<0.01$ ). This risk reduction in elderly patients is comparable with the risk reduction in the overall study population of the FREEDOM trial. ${ }^{59}$

Another analysis of the FREEDOM trial by McClung et al in 2012 confirmed that denosumab reduces the risk of vertebral fractures to the same extent in subjects aged $\geq 75$ years $(\mathrm{RR}=0.36 ; 95 \% \mathrm{CI}=0.25-0.53)$ as in subjects aged $<75$ years $(\mathrm{RR}=0.30 ; 95 \% \mathrm{CI}=0.22-0.41$; interaction $P$-value $=0.482) .{ }^{61}$ Furthermore, the effect on nonvertebral fractures was similar in persons aged $>75$ years $(\mathrm{RR}=0.84 ; 95 \% \mathrm{CI}=0.63-1.12)$ and $<75$ years $(\mathrm{RR}=0.78$; 95\% CI $=0.63-0.96$; interaction $P$-value $=0.642$ ).

Thus, denosumab is an effective treatment to prevent vertebral and hip fractures in the elderly. ${ }^{60,61}$ This result was in contrast to the bisphosphonates where no significant reduction in hip fracture risk could be shown for risedronate and zoledronic acid in the elderly, although, as mentioned, this might be explained by the lack of statistical power in these subgroup analyses. ${ }^{46,47,56}$ However, it is tempting to speculate that this observation of hip fracture reduction with denosumab is due to its mechanism of action, which is different from the mechanism of action of bisphosphonates, with distinct effects on cortical bone. ${ }^{62}$ Cortical porosity is indeed one of the main determinants of nonvertebral fracture risk, including hip fracture risk.

\section{Strontium ranelate}

The antifracture efficacy of strontium ranelate, which has a dual mode of action of both increasing bone formation and reducing bone resorption, was established by two trials: the Spinal Osteoporosis Therapeutic Intervention (SOTI) trial (mean age $=69.3$ years) and the Treatment of Peripheral Osteoporosis (TROPOS; mean age $=76.7$ years) ${ }^{63,64}$

A preplanned pooled analysis of both SOTI and TROPOS was undertaken by Seeman et al to confirm these results in patients aged $\geq 80$ years (mean age $=83.5$ years). After 3 years, the risk of vertebral fractures was reduced by $32 \%(\mathrm{RR}=0.68$; $95 \% \mathrm{CI}=0.50-0.92)$ and the risk of nonvertebral fractures was reduced by $31 \%(\mathrm{RR}=0.69 ; 95 \% \mathrm{CI}=0.52-0.92) .{ }^{65}$ After 5 years, the risk of vertebral fractures was reduced by $31 \%$ (RR $=0.69 ; 95 \% \mathrm{CI}=0.52-0.92$ ) and the risk of non-vertebral fractures was reduced by $27 \%(\mathrm{RR}=0.73 ; 95 \% \mathrm{CI}=0.57-0.95){ }^{5}$ The number needed to treat to prevent vertebral and nonvertebral fractures was lower in women aged $\geq 80$ years than in younger women. This is because a similar RR reduction of strontium ranelate in both age-groups will avert more fractures in the older age-group that has a higher baseline fracture risk. ${ }^{65}$ Statistical significance of hip fracture risk reduction was not 
reached in both the trials, but these analyses were not designed to quantify the reduction in hip fracture risk. ${ }^{5,65}$ Thus, these analyses showed a significant reduction in the risk of both vertebral and nonvertebral fractures in persons aged $\geq 80$ years treated with strontium ranelate.

\section{Teriparatide}

Daily subcutaneous injections of teriparatide, a biosynthetic PTH analog, reduces the risk of vertebral and nonvertebral fractures, as shown in the Fracture Prevention Trial (FPT) in postmenopausal women with a prior vertebral fracture (mean age $=69.5$ years). ${ }^{66}$

A prespecified subgroup analysis of the FPT study was undertaken in 2006 by Boonen et al to investigate the effect of teriparatide in persons aged $\geq 75$ years (mean age $=78.3$ years $).{ }^{67}$ In this subgroup, 5.2\% in the teriparatide group and $15.1 \%$ in the placebo group had a new vertebral fracture after 19 months $(\mathrm{RR}=0.35 ; P<0.05)$. Treatmentby-age interaction was not significant $(P=0.99)$, indicating that the effect of teriparatide was not statistically different in younger versus older patients. Also in the older subgroup, $3.2 \%$ of the elderly women on teriparatide and $4.2 \%$ on placebo had a new nonvertebral fracture $(\mathrm{RR}=0.75 ; P=0.661)$. The treatment-by-age interaction was again not significant $(P=0.42)$. The nonsignificant effect on nonvertebral fracture risk in the very elderly can be explained by the small number of nonvertebral fractures in the older subgroup. As a result, this analysis was not sufficiently powered to show a statistically significant reduction in the risk of nonvertebral fractures in women aged $\geq 75$ years or to detect small differences in the relative treatment effect on nonvertebral fractures in the younger and older subgroups. ${ }^{67}$ Hip fracture incidence was not a primary endpoint of this study. ${ }^{67}$ Therefore, age does not affect the efficacy of teriparatide in preventing vertebral and nonvertebral fractures.

\section{Safety of osteoporosis drugs}

The large pivotal fracture trials have shown that, in general, osteoporosis treatment is well tolerated, with adverse events that tend to be mild to moderate. For an in-depth review of the adverse reactions in postmenopausal osteoporosis, the present study refers to some recent overviews. ${ }^{68,69}$ However, there are limited data on how this applies to the very elderly population. ${ }^{70}$ Issues concerning drug therapy in the very elderly include reduced intestinal absorption, metabolism and excretion of drugs, concomitant disorders, polypharmacy and therapeutic incompliance. ${ }^{69}$ For example, aging is associated with a decline in renal function. As $\sim 50 \%$ of the bisphosphonates are excreted by the kidney, impaired renal function may result in an accumulation of the bisphosphonates, which potentially affects their efficacy and safety. ${ }^{71}$

In the next section, the available evidence on the safety of the currently available pharmacological osteoporosis therapies in the very elderly is discussed. Table 2 summarizes the most relevant adverse events reported in the clinical trials in this population. Antiresorptive therapy may also be associated with very rare but severe adverse events, such as atypical femoral fractures and osteonecrosis of the jaw. To the authors' knowledge, there is no evidence that these events are independently associated with age. ${ }^{72}$

\section{Alendronate}

The post hoc analysis of the FIT-I in postmenopausal women aged $\geq 75$ years $^{46}$ and the pooled analysis from both the FIT $\operatorname{arms}^{47}$ did not report safety data in the very elderly. In the trial of Axelsson et $\mathrm{al}^{48}$ in women with a mean age of 82.4 years, adverse events such as esophagitis, dyspepsia, and acid reflux were not more common in the higher age quartiles than in the lower age quartiles. ${ }^{48}$

\section{Risedronate}

Women aged $\geq 80$ years in the HIP trial ${ }^{51}$ had a slightly higher incidence of death, other serious adverse events, and withdrawals due to adverse events as compared to younger women. However, the overall frequency and types of adverse events, including those involving the upper gastrointestinal tract, were similar in the risedronate and placebo groups, regardless of age. In addition, in women aged $\geq 80$ years in the pooled analysis of the VERT-NA, VERT-MN, and HIP trials, ${ }^{52}$ adverse events were similar in the risedronate and placebo groups. Even in the very elderly with active gastrointestinal tract disease at baseline or on aspirin, nonsteroidal anti-inflammatory drugs, or proton pump inhibitors, the incidence of upper gastrointestinal adverse events was the same in both the treatment groups.

Thus, according to these data, oral bisphosphonates are well tolerated in the very elderly and, even in those at a high risk of gastrointestinal events, not associated with an increased frequency of these adverse events as compared to placebo. However, in clinical practice, treatment with oral bisphosphonates may be challenging in the very elderly, as the stringent intake instructions (eg, to stay upright for at least 30 minutes after taking the medication) may be difficult for physically or cognitively impaired elderly. While, as mentioned, data from RCTs indicated that the gastrointestinal side effects of oral bisphosphonates are 
similar in older and younger individuals, inappropriate administration increases the risk of these adverse events. ${ }^{71}$ Furthermore, oral osteoporosis medication (together with calcium and vitamin D supplementation) increases the pill burden in the very elderly, which may lead to lower compliance. An intravenous bisphosphonate, such as zoledronic acid, is an alternative in the very elderly that cannot tolerate or adhere to oral bisphosphonates.

\section{Zoledronic acid}

In the post hoc analysis of the HORIZON-PFT and RFT in women aged $\geq 75$ years, ${ }^{56}$ the incidence of adverse events and postdose symptoms occurring within 3 days of study drug infusion, such as pyrexia, myalgia, and influenza-like illness, was higher with zoledronic acid than with placebo. However, the incidence of serious adverse events and death were similar in the two treatment arms. In addition, an increased risk of atrial fibrillation, suggested in the HORIZON-PFT, ${ }^{57}$ which could be a concern in the elderly, was not observed in the very elderly on zoledronic acid. ${ }^{56}$

In this post hoc analysis, which excluded individuals with a creatinine clearance $<30 \mathrm{~mL} / \mathrm{min}$, the incidence of renal events, such as an increase in creatinine clearance, was similar in the zoledronic acid and the placebo groups. ${ }^{56}$ There were no data in patients with severe kidney impairment. Due to some very rare cases of acute renal failure following zoledronic acid, the European Medicine Agency (EMA) specified that this therapy is contraindicated in patients with a creatinine clearance $<35 \mathrm{~mL} / \mathrm{min}^{73}$

\section{Denosumab}

In general, denosumab was well tolerated by the subjects in the FREEDOM trial. ${ }^{59}$ In the post hoc analysis in women aged $\geq 75$ years ${ }^{60}$ no significant differences were noted in the safety profile between placebo- and denosumab-treated subjects. The incidences of the adverse events were similar to those reported for the overall FREEDOM population. Moreover, the treatment efficacy of denosumab was not affected by renal function; therefore, the elderly with renal impairment will experience the same antifracture efficacy as patients with normal renal function. ${ }^{74}$ However, as the use of denosumab is associated with a high rate of severe hypocalcemia in patients with advanced chronic kidney disease, close monitoring and replacement of calcium and vitamin $\mathrm{D}$ are required to avoid the development of hypocalcemia in these patients.

\section{Strontium ranelate}

The preplanned pooled analysis of SOTI and TROPOS in women aged $80-100$ years showed that strontium ranelate safely reduces the risk of vertebral and nonvertebral fractures during 3 and 5 years. ${ }^{5,65}$ After 5 years, headaches, deep venous thromboembolic events, and seizures were significantly more common in the strontium ranelate group, but no case of allergic reaction was reported. Treatment with strontium ranelate increased the number and quality of remaining years of life. ${ }^{5}$ However, in patients who were frail according to the criteria of Fried et al, ${ }^{75}$ Strontium ranelate was associated with a higher incidence of adverse events, serious adverse events, emergent adverse events, and withdrawals due to adverse events as compared to intermediate and nonfrail participants. ${ }^{76}$ Apart from age, this could relate to comorbidity, polypharmacy, and frailty itself.

The recent finding of an increased risk of cardiac events, including myocardial infarction, has limited the use of strontium ranelate in the very elderly. ${ }^{77}$ This safety concern emerged from new safety data from additional clinical studies in male osteoporosis and osteoarthritis. The analysis of the cardiovascular data led the EMA to recommend a change in the indication of strontium ranelate. ${ }^{77}$ Strontium ranelate remains a useful therapeutic alternative in elderly patients with severe osteoporosis who are unable to take other osteoporosis treatments, but it is contraindicated in those with uncontrolled hypertension, established, current or past history of ischemic heart disease, peripheral arterial disease, and/or cerebrovascular disease. ${ }^{78}$

\section{Teriparatide}

In the post hoc analysis of the FPT in women aged $\geq 75$ years, ${ }^{67}$ there was no increase in adverse events in women treated with teriparatide compared with placebo. In contrast, back pain, cataract, and pruritus were significantly less common in those treated with teriparatide. The treatment-by-age interaction ( $\geq 75$ years versus $<75$ years) was not significant for the important adverse events. Only diarrhea was reported more frequently, whereas cataract, deafness, pruritus, and weight loss were reported less frequently in the older compared to the younger age-group. Thus, in the elderly, the safety profile of teriparatide is similar to placebo. In clinical practice, the major disadvantages of teriparatide are the cost and the daily subcutaneous administration, which may be a burden for older patients.

\section{Summary of safety of osteoporosis drugs}

Data from the post hoc and preplanned analyses in the very elderly showed that currently available osteoporosis therapies are relatively safe, with no significant differences in the incidence of most adverse events in the treated group compared with the placebo group. Overall, the incidence of 
adverse events in the very elderly was similar to that reported in the general population. However, in real life, specific issues such as comorbidity and polypharmacy should be taken into account in the very elderly and may influence the choice of therapy.

\section{Conclusion}

Osteoporosis is one of the most common age-associated conditions and a major cause of fracture risk. In old age, osteoporosis and osteoporotic fractures tend to occur in a particularly frail subset of population. The treatment of osteoporosis is of particular concern in the elderly because of the substantial burden of osteoporotic fractures in terms of morbidity, mortality, and economic cost.

It is never too late to treat osteoporosis, not even in elderly patients with the most severe degree of osteoporosis and who have already sustained osteoporotic fractures. Calcium and vitamin D supplementation is an essential but not sufficient component of the management of osteoporosis in old age. Adding osteoporosis treatment appears to be safe and reduces the risk of fractures even more, at least in older individuals with documented osteoporosis and for vertebral fractures, and possibly also for hip fractures. Osteoporosis treatment may even be more effective in frail elderly patients with documented osteoporosis than in younger patients, with more fractures averted and even lower numbers to treat, ultimately leading to reduced morbidity and even mortality.

\section{Disclosure}

The authors report no conflicts of interest in this work.

\section{References}

1. Cosman F, de Beur SJ, LeBoff MS, et al. Clinician's guide to prevention and treatment of osteoporosis. Osteoporos Int. 2014;25(10): 2359-2381.

2. Cooper C, Campion G, Melton LJ. Hip fractures in the elderly: a worldwide projection. Osteoporosis Int. 1992;2(6):285-289.

3. Grados F, Marcelli C, Dargent-Molina P, et al. Prevalence of vertebral fractures in French women older than 75 years from the EPIDOS study. Bone. 2004;34(2):362-367.

4. Nguyen TV, Center JR, Sambrook PN, Eisman JA. Risk factors for proximal humerus, forearm, and wrist fractures in elderly men and women: the Dubbo Osteoporosis Epidemiology Study. Am J Epidemiol. 2001; 153(6):587-595.

5. Seeman E, Boonen S, Borgstrom F, et al. Five years treatment with strontium ranelate reduces vertebral and nonvertebral fractures and increases the number and quality of remaining life-years in women over 80 years of age. Bone. 2010;46(4):1038-1042.

6. Sambrook P, Cooper C. Osteoporosis. Lancet. 2006;367(9527): 2010-2018.

7. Kanis JA, Borgstrom F, Compston J, et al. SCOPE: a scorecard for osteoporosis in Europe. Arch Osteoporos. 2013;8:144.

8. Gielen E, Verschueren S, O’Neill TW, et al. Musculoskeletal frailty: a geriatric syndrome at the core of fracture occurrence in older age. Calcif Tissue Int. 2012;91(3):161-177.
9. Boonen S, Autier P, Barette M, Vanderschueren D, Lips P, Haentjens P Functional outcome and quality of life following hip fracture in elderly women: a prospective controlled study. Osteoporos Int. 2004;15(2): 87-94.

10. Leibson CL, Tosteson AN, Gabriel SE, Ransom JE, Melton LJ. Mortality, disability, and nursing home use for persons with and without hip fracture: a population-based study. J Am Geriatr Soc. 2002;50(10):1644-1650.

11. Schnell S, Friedman SM, Mendelson DA, Bingham KW, Kates SL. The 1-year mortality of patients treated in a hip fracture program for elders. Geriatr Orthop Surg Rehabil. 2010;1(1):6-14.

12. International Osteoporosis Foundation [webpage on the Internet]. Facts and statistics. Available from: https://www.iofbonehealth.org/ facts-statistics. Accessed December 1, 2016.

13. Gielen E, Vanderschueren D, Callewaert F, Boonen S. Osteoporosis in men. Best Prac Res Clin Endocrinol Metab. 2011;25(2):321-335.

14. Haentjens P, Magaziner J, Colon-Emeric CS, et al. Meta-analysis: excess mortality after hip fracture among older women and men. Ann Intern Med. 2010;152(6):380-390.

15. Feldstein A, Elmer PJ, Orwoll E, Herson M, Hillier T. Bone mineral density measurement and treatment for osteoporosis in older individuals with fractures: a gap in evidence-based practice guideline implementation. Arch Intern Med. 2003;163(18):2165-2172.

16. Rosen CJ, Abrams SA, Aloia JF, et al. IOM committee members respond to Endocrine Society vitamin D guideline. J Clin Endocrinol Metab. 2012;97(4):1146-1152.

17. Lips P. Vitamin D deficiency and secondary hyperparathyroidism in the elderly: consequences for bone loss and fractures and therapeutic implications. Endocr Rev. 2001;22(4):477-501.

18. Holick MF, Matsuoka LY, Wortsman J. Age, vitamin D, and solar ultraviolet. Lancet. 1989;2(8671):1104-1105.

19. Mithal A, Wahl DA, Bonjour JP, et al. Global vitamin D status and determinants of hypovitaminosis D. Osteoporos Int. 2009;20(11): 1807-1820.

20. Kuchuk NO, Pluijm SM, van Schoor NM, Looman CW, Smit JH, Lips P. Relationships of serum 25-hydroxyvitamin D to bone mineral density and serum parathyroid hormone and markers of bone turnover in older persons. J Clin Endocrinol Metab. 2009;94(4):1244-1250.

21. Beaudart C, Buckinx F, Rabenda V, et al. The effects of vitamin D on skeletal muscle strength, muscle mass, and muscle power: a systematic review and meta-analysis of randomized controlled trials. J Clin Endocrinol Metab. 2014;99(11):4336-4345.

22. Dawson-Hughes B, Mithal A, Bonjour JP, et al. IOF position statement: vitamin D recommendations for older adults. Osteoporos Int. 2010; 21(7):1151-1154.

23. Bouillon R, Van Schoor NM, Gielen E, et al. Optimal vitamin D status: a critical analysis on the basis of evidence-based medicine. J Clin Endocrinol Metab. 2013;98(8):E1283-E1304.

24. American Geriatrics Society Workgroup on Vitamin D Supplementation for Older Adults. Recommendations abstracted from the American Geriatrics Society Consensus Statement on vitamin D for prevention of falls and their consequences. J Am Geriatr Soc. 2014;62(1):147-152.

25. Lappe JM, Binkley N. Vitamin D and Sarcopenia/Falls. J Clin Densitom. 2015;18(4):478-482.

26. Bischoff-Ferrari HA, Dawson-Hughes B, Platz A, et al. Effect of highdosage cholecalciferol and extended physiotherapy on complications after hip fracture: a randomized controlled trial. Arch Intern Med. 2010;170(9):813-820.

27. Bischoff-Ferrari HA, Dawson-Hughes B, Orav EJ, et al. Monthly high-dose vitamin $\mathrm{D}$ treatment for the prevention of functional decline: a randomized clinical trial. JAMA Intern Med. 2016;176(2):175-183.

28. Ross AC, Manson JE, Abrams SA, et al. The 2011 report on dietary reference intakes for calcium and vitamin D from the Institute of Medicine: what clinicians need to know. J Clin Endocrinol Metab. 2011;96(1):53-58.

29. Institute of Medicine, editor. Dietary Reference Intakes for Calcium and Vitamin D. Washington, DC: The National Academies Press; 2011.

30. Holick MF, Binkley NC, Bischoff-Ferrari HA, et al. Evaluation, treatment, and prevention of vitamin D deficiency: an Endocrine Society clinical practice guideline. J Clin Endocrinol Metab. 2011;96(7):1911-1930. 
31. Bolland MJ, Grey A, Gamble GD, Reid IR. The effect of vitamin D supplementation on skeletal, vascular, or cancer outcomes: a trial sequential meta-analysis. Lancet Diabetes Endocrinol. 2014;2(4):307-320.

32. Bischoff-Ferrari HA, Orav EJ, Willett WC, Dawson-Hughes B. The effect of vitamin D supplementation on skeletal, vascular, or cancer outcomes. Lancet Diabetes Endocrinol. 2014;2(5):363-364.

33. Boonen S, Lips P, Bouillon R, Bischoff-Ferrari HA, Vanderschueren D, Haentjens P. Need for additional calcium to reduce the risk of hip fracture with vitamin d supplementation: evidence from a comparative metaanalysis of randomized controlled trials. J Clin Endocrinol Metab. 2007;92(4):1415-1423.

34. DIPART (Vitamin D Individual Patient Analysis of Randomized Trials) Group. Patient level pooled analysis of 68500 patients from seven major vitamin D fracture trials in US and Europe. BMJ. 2010;340:b5463.

35. Avenell A, Gillespie WJ, Gillespie LD, O'Connell D. Vitamin D and vitamin $\mathrm{D}$ analogues for preventing fractures associated with involutional and post-menopausal osteoporosis. Cochrane Database Syst Rev. 2009;2:CD000227.

36. Jackson C, Gaugris S, Sen SS, Hosking D. The effect of cholecalciferol (vitamin D3) on the risk of fall and fracture: a meta-analysis. QJM. 2007; 100(4):185-192.

37. Jackson RD, LaCroix AZ, Gass M, et al. Calcium plus vitamin D supplementation and the risk of fractures. $N$ Engl J Med. 2006;354(7): 669-683.

38. Grant AM, Avenell A, Campbell MK, et al. Oral vitamin D3 and calcium for secondary prevention of low-trauma fractures in elderly people (Randomised Evaluation of Calcium Orvitamin D, RECORD): a randomised placebo-controlled trial. Lancet. 2005;365(9471):1621-1628.

39. Boonen S, Vanderschueren D, Haentjens P, Lips P. Calcium and vitamin D in the prevention and treatment of osteoporosis - a clinical update. J Intern Med. 2006;259(6):539-552.

40. Bolland MJ, Avenell A, Baron JA, et al. Effect of calcium supplements on risk of myocardial infarction and cardiovascular events: meta-analysis. BMJ. 2010;341:c3691.

41. Bolland MJ, Grey A, Avenell A, Gamble GD, Reid IR. Calcium supplements with or without vitamin D and risk of cardiovascular events: reanalysis of the Women's Health Initiative limited access dataset and meta-analysis. BMJ. 2011;342:d2040.

42. Verbrugge F, Gielen E, Milisen K, Boonen S. Who should receive calcium and vitamin D supplementation? Age Ageing. 2012;41(5):576-580.

43. Black DM, Cummings SR, Karpf DB, et al. Randomised trial of effect of alendronate on risk of fracture in women with existing vertebral fractures. Fracture Intervention Trial Research Group. Lancet. 1996; 348(9041):1535-1541.

44. Cummings SR, Black DM, Thompson DE, et al. Effect of alendronate on risk of fracture in women with low bone density but without vertebral fractures: results from the Fracture Intervention Trial. JAMA. 1998; 280(24):2077-2082.

45. Black DM, Thompson DE, Bauer DC, et al. Fracture risk reduction with alendronate in women with osteoporosis: the Fracture Intervention Trial. FIT Research Group. J Clin Endocrinol Metab. 2000;85(11): 4118-4124.

46. Ensrud KE, Black DM, Palermo L, et al. Treatment with alendronate prevents fractures in women at highest risk: results from the Fracture Intervention Trial. Arch Int Med. 1997;157(22):2617-2624.

47. Hochberg MC, Thompson DE, Black DM, et al. Effect of alendronate on the age-specific incidence of symptomatic osteoporotic fractures. J Bone Miner Res. 2005;20(6):971-976.

48. Axelsson K, Lundh D, Lorentzon M. Alendronate treatment is associated with reduced fracture risk and maintained safety in the oldest old. Poster presented at: ASBMR Annual Meeting; 2016; Atlanta, GA.

49. Harris ST, Watts NB, Genant HK, et al. Effects of risedronate treatment on vertebral and nonvertebral fractures in women with postmenopausal osteoporosis: a randomized controlled trial. Vertebral Efficacy With Risedronate Therapy (VERT) Study Group. JAMA. 1999;282(14): 1344-1352.
50. Reginster J, Minne HW, Sorensen OH, et al. Randomized trial of the effects of risedronate on vertebral fractures in women with established postmenopausal osteoporosis. Vertebral Efficacy with Risedronate Therapy (VERT) Study Group. Osteoporos Int. 2000;11(1):83-91.

51. McClung MR, Geusens P, Miller PD, et al. Effect of risedronate on the risk of hip fracture in elderly women. Hip Intervention Program Study Group. N Engl J Med. 2001;344(5):333-340.

52. Boonen S, McClung MR, Eastell R, El-Hajj Fuleihan G, Barton IP, Delmas P. Safety and efficacy of risedronate in reducing fracture risk in osteoporotic women aged 80 and older: implications for the use of antiresorptive agents in the old and oldest old. J Am Geriatr Soc. 2004; 52(11):1832-1839.

53. Tom SE, Adachi JD, Anderson FA Jr, et al. Frailty and fracture, disability, and falls: a multiple country study from the global longitudinal study of osteoporosis in women. J Am Geriatr Soc. 2013;61(3):327-334.

54. Cryer B, Bauer DC. Oral bisphosphonates and upper gastrointestinal tract problems: what is the evidence? Mayo Clin Proc. 2002;77(10): 1031-1043.

55. Lo JC, Pressman AR, Omar MA, Ettinger B. Persistence with weekly alendronate therapy among postmenopausal women. Osteoporos Int. 2006;17(6):922-928.

56. Boonen S, Black DM, Colon-Emeric CS, et al. Efficacy and safety of a once-yearly intravenous zoledronic acid $5 \mathrm{mg}$ for fracture prevention in elderly postmenopausal women with osteoporosis aged 75 and older. $J$ Am Geriatr Soc. 2010;58(2):292-299.

57. Black DM, Delmas PD, Eastell R, et al. Once-yearly zoledronic acid for treatment of postmenopausal osteoporosis. $N$ Engl J Med. 2007; 356(18):1809-1822.

58. Lyles KW, Colon-Emeric CS, Magaziner JS, et al. Zoledronic acid in reducing clinical fracture and mortality after hip fracture. $N$ Engl $J$ Med. 2007;357(18):1799-1809.

59. Cummings SR, San Martin J, McClung MR, et al. Denosumab for prevention of fractures in postmenopausal women with osteoporosis. N Engl J Med. 2009;361(8):756-765.

60. Boonen S, Adachi JD, Man Z, et al. Treatment with denosumab reduces the incidence of new vertebral and hip fractures in postmenopausal women at high risk. J Clin Endocrinol Metab. 2011;96(6): 1727-1736.

61. McClung MR, Boonen S, Torring O, et al. Effect of denosumab treatment on the risk of fractures in subgroups of women with postmenopausal osteoporosis. J Bone Miner Res. 2012;27(1):211-218.

62. Genant HK, Libanati C, Engelke K, et al. Improvements in hip trabecular, subcortical, and cortical density and mass in postmenopausal women with osteoporosis treated with denosumab. Bone. 2013;56(2): 482-488.

63. Meunier PJ, Roux C, Seeman E, et al. The effects of strontium ranelate on the risk of vertebral fracture in women with postmenopausal osteoporosis. N Engl J Med. 2004;350(5):459-468.

64. Reginster JY, Seeman E, De Vernejoul MC, et al. Strontium ranelate reduces the risk of nonvertebral fractures in postmenopausal women with osteoporosis: Treatment of Peripheral Osteoporosis (TROPOS) study. J Clin Endocrinol Metab. 2005;90(5):2816-2822.

65. Seeman E, Vellas B, Benhamou C, et al. Strontium ranelate reduces the risk of vertebral and nonvertebral fractures in women eighty years of age and older. J Bone Miner Res. 2006;21(7):1113-1120.

66. Neer RM, Arnaud CD, Zanchetta JR, et al. Effect of parathyroid hormone (1-34) on fractures and bone mineral density in postmenopausal women with osteoporosis. N Engl J Med. 2001;344(19):1434-1441.

67. Boonen S, Marin F, Mellstrom D, et al. Safety and efficacy of teriparatide in elderly women with established osteoporosis: bone anabolic therapy from a geriatric perspective. J Am Geriatr Soc. 2006;54(5):782-789.

68. Rizzoli R, Reginster JY, Boonen S, et al. Adverse reactions and drugdrug interactions in the management of women with postmenopausal osteoporosis. Calcif Tissue Int. 2011;89(2):91-104.

69. Rizzoli R, Branco J, Brandi ML, et al. Management of osteoporosis of the oldest old. Osteoporos Int. 2014;25(11):2507-2529. 
70. Inderjeeth CA, Foo AC, Lai MM, Glendenning P. Efficacy and safety of pharmacological agents in managing osteoporosis in the old old: review of the evidence. Bone. 2009;44(5):744-751.

71. Vondracek SF, Linnebur SA. Diagnosis and management of osteoporosis in the older senior. Clin Interv Aging. 2009;4:121-136.

72. Low A. Should all elderly women receive bisphosphonates to prevent osteoporotic fractures? Can J Hosp Pharm. 2012;65(1):45-48.

73. European Medicines Agency. Zoledronic acid. Summary of product characteristics. Available from: http://www.emea.europa.eu. Accessed December 1, 2016.

74. Jamal SA, Ljunggren O, Stehman-Breen C, et al. Effects of denosumab on fracture and bone mineral density by level of kidney function. J Bone Miner Res. 2011;26(8):1829-1835.
75. Fried LP, Tangen CM, Walston J, et al. Frailty in older adults: evidence for a phenotype. J Gerontol A Biol Sci Med Sci. 2001;56(3):M146-M156.

76. Rolland Y, Abellan Van Kan G, Gillette-Guyonnet S, Roux C, Boonen S, Vellas B. Strontium ranelate and risk of vertebral fractures in frail osteoporotic women. Bone. 2011;48(2):332-338.

77. European Medicines Agency. Protelos-H-C-560-PSU-31: EPARAssessment Report-Periodic safety update report. 2013. Available from: http://www.ema.europa.eu/docs/en_GB/document_library/EPAR_Assessment_Report_-_Variation/human/000560/WC500147168.pdf. Accessed February 15, 2017.

78. Reginster JY. Cardiac concerns associated with strontium ranelate. Expert Opin Drug Saf. 2014;13(9):1209-1213.
Clinical Interventions in Aging

\section{Publish your work in this journal}

Clinical Interventions in Aging is an international, peer-reviewed journal focusing on evidence-based reports on the value or lack thereof of treatments intended to prevent or delay the onset of maladaptive correlates of aging in human beings. This journal is indexed on PubMed Central, MedLine,

\section{Dovepress}

CAS, Scopus and the Elsevier Bibliographic databases. The manuscript management system is completely online and includes a very quick and fair peer-review system, which is all easy to use. Visit http://www.dovepress. com/testimonials.php to read real quotes from published authors. 